\title{
Improved dq-Axes Model of PMSM Considering Airgap Flux Harmonics and Saturation
}

Fasil, Muhammed; Antaloae, Ciprian; Mijatovic, Nenad; Jensen, Bogi Bech; Holbøll, Joachim

Published in:

IEEE Transactions on Applied Superconductivity

Link to article, DOI:

$10.1109 /$ tasc.2016.2524021

Publication date:

2016

Document Version

Peer reviewed version

Link back to DTU Orbit

Citation (APA):

Fasil, M., Antaloae, C., Mijatovic, N., Jensen, B. B., \& Holbøll, J. (2016). Improved dq-Axes Model of PMSM Considering Airgap Flux Harmonics and Saturation. IEEE Transactions on Applied Superconductivity, 26(4), [5202705]. https://doi.org/10.1109/tasc.2016.2524021

\section{General rights}

Copyright and moral rights for the publications made accessible in the public portal are retained by the authors and/or other copyright owners and it is a condition of accessing publications that users recognise and abide by the legal requirements associated with these rights.

- Users may download and print one copy of any publication from the public portal for the purpose of private study or research.

- You may not further distribute the material or use it for any profit-making activity or commercial gain

- You may freely distribute the URL identifying the publication in the public portal 


\title{
Improved $d q$-axes Model of PMSM Considering Airgap Flux Harmonics and Saturation
}

\author{
M. Fasil, C. Antaloae, N. Mijatovic, B. B. Jensen and J. Holboll
}

\begin{abstract}
In this work, the classical linear model of a permanent magnet synchronous motor (PMSM) is modified by adding $d$ and $q$-axes harmonic inductances so that the modified model can consider non-linearities present in an interior permanent magnet (IPM) motor. Further, a method has been presented to assess the effect of saturation and cross-saturation on constant torque curves of PMSM. Two IPM motors with two different rotor topologies and different specifications are designed to evaluate the effect of saturation on synchronous and harmonic inductances, and on operating points of the machines.
\end{abstract}

Index Terms-Interior permanent magnet machine, permanent magnet synchronous machine, harmonic inductances, saturation, field weakening.

\section{INTRODUCTION}

$\mathbf{P}$ ERMANENT magnet synchronous machines (PMSM) are a popular choice in electric powertrain because of benefits such as high power density, high torque density and wide constant power operation [1]. The classical model of PMSM neglects non-linearities caused by the higher order airgap flux harmonics (greater than second) and the saturated magnetic flux path [2]. This was not an issue in earlier versions of PMSM drives as they were mostly using surface permanent magnet (SPM) machines. The large effective airgap of SPM machines limits the influence of armature reaction on machine parameters. The applications like drives for traction require extended constant power operation and interior permanent magnet (IPM) machines, which utilises reluctance torque along with magnet torque, are more suitable compared to SPM machines [3]-[6]. The IPM machines has narrow airgap and, therefore, the armature current influences amplitude of harmonic fluxes, the saturation level, core losses, and $d q$-axes inductances [7].

Several studies have been carried out to estimate the effect of saturation on parameters of IPM machines and to improve the accuracy of classical $d q$-axes model of PMSM [8]-[11]. In [12], the authors presented a comparison between the classical

This work was supported by EU-FP7 NANOPYME Project (No. 310516). Authors would like to thank AVL Powertrain Ltd, UK for their help in carrying out the research. (Corresponding author: M. Fasil)

M. Fasil is with Department of Electrical Engineering, Technical University of Denmark, Kgs. Lyngby, 2800, Denmark (e-mail: mfasil@elektro.dtu.dk).

C. Antaloae is with AVL Powertrain UK Ltd, Coventry, CV4 7EZ, United Kingdom (email: ciprian.antaloae@avl.com)

N. Mijatovic is with Department of Electrical Engineering, Technical University of Denmark, Kgs. Lyngby, 2800, Denmark (e-mail: nm@elektro.dtu.dk).

B. B. Jensen is with Department of Science and Technology, University of the Faroe Islands, Torshavn, FO-100, Faroe Islands (email: bogibj@ setur.fo)

J. Holboll is with Department of Electrical Engineering, Technical University of Denmark, Kgs. Lyngby, 2800, Denmark (e-mail: jh@elektro.dtu.dk). $d q$-axes model and the finite element (FE) model of an IPM machine. In their study, an error of less than $10 \%$ in core-loss at base speed has increased to more than $75 \%$ at four times the base speed. The authors proposed adding harmonic inductance to $d q$-axes model of IPM machine and this helps to model the increased core loss in field weakening mode. The authors used same inductances, which was obtained by dividing the sum of magnitudes of all higher order flux linkage harmonics with magnitude of phase current, to both $d$ and $q$ equivalent circuits. Even though, the model was closer to test results compared to the classical model, considerable deviations were observed. In this work, the model presented in [12] was modified by considering harmonic fluxes that are resolved into $d$-axis and $q$-axis to calculate harmonic inductances of $d$ and $q$ equivalent circuits. In addition, the effect of saturation on operating point of IPM machine when it is operating under maximum torque per ampere (MTPA) control has been studied. Two IPM machines with different rotor topologies, shown in Fig. 1, are designed to demonstrate the proposed concepts.

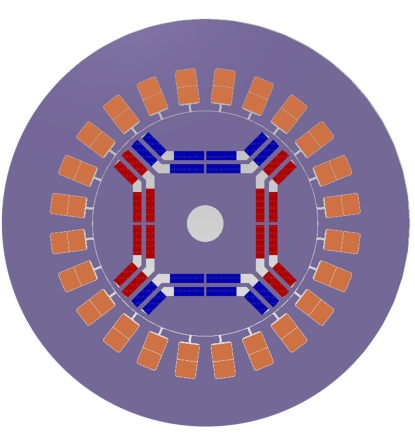

(a)

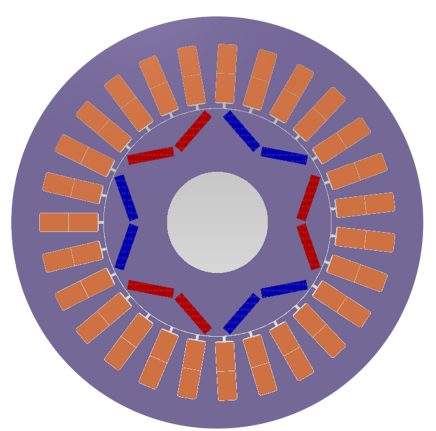

(b)
Fig. 1: IPM topologies used for calculating $d q$-axis equivalent circuit parameters. (a) Two layer angled barrier magnets. (b) Embedded variable orientation magnets.

\section{THE $d q$-AXES MODEL OF PMSM CONSIDERING HARMONIC INDUCTANCES}

The flowchart shown in Fig. 2, describes the procedure for calculating the fundamental (or synchronous) and harmonic components of $d q$-axes inductances, considering saturation and cross-saturation. The $d$-axis and $q$-axis harmonic components of flux linkages, $\psi_{d n}$ and $\psi_{q n}$ can be obtained from the Fourier analysis of airgap flux density distribution as [13]

$\psi_{d n}=B_{d n} \frac{D L_{s t k}}{p} k_{w n} T_{p h} ; \quad \psi_{q n}=B_{q n} \frac{D L_{s t k}}{p} k_{w n} T_{p h}$ 


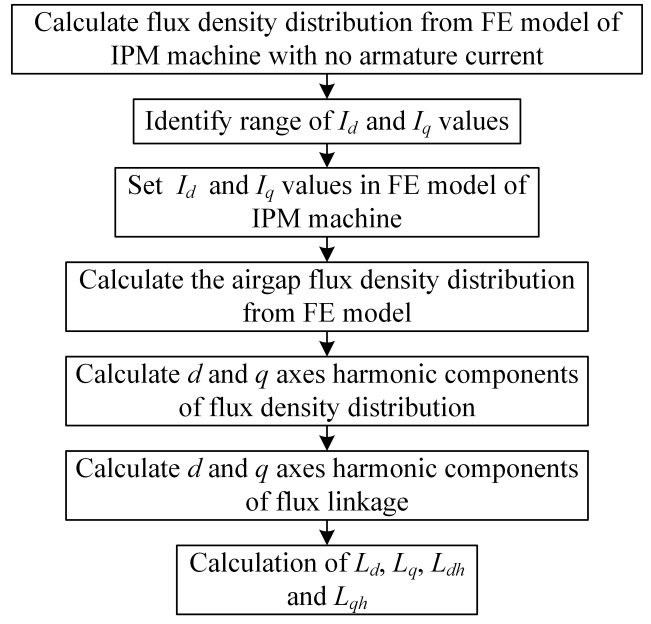

Fig. 2: The flowchart to calculate fundamental and harmonic inductances from the FE model of IPM machine

where $B_{d n}$ and $B_{q n}$ are values of real and imaginary parts of the $n^{\text {th }}$ harmonic component of flux density distribution under load, $D$ is the outer diameter of the airgap, $L_{s t k}$ is the stack length of the machine, $p$ is the number of pole pairs of the machine, $k_{w n}$ is $n^{\text {th }}$ harmonic winding factor and $T_{p h}$ is the number of turns in series per phase. The $d$-axis and $q$-axis synchronous inductances are calculated as

$$
L_{d}=\frac{\psi_{1 M d}-\psi_{d 1}}{I_{d}} ; \quad L_{q}=\frac{\psi_{q 1}}{I_{q}}
$$

where $\psi_{1 M d}$ is the fundamental component of the $d$-axis flux linkage due to the magnet flux alone. The effect of all higher order harmonics of flux linkage is represented by harmonic inductances, $L_{d h}$ and $L_{q h}$ and they can be calculated as

$$
L_{d h}=\sum_{i=5,7, \ldots}^{\infty} \frac{\psi_{d 0 i}-\psi_{d i}}{I_{d}} ; \quad L_{q h}=\sum_{i=5,7, \ldots}^{\infty} \frac{\psi_{q i}}{I_{q}}
$$

where $\psi_{d 0 i}$ is the $i^{\text {th }}$ harmonic flux linkage due to magnet flux alone. The modified $d q$-axis equivalent circuits of IPM machine considering harmonic inductances are shown in Fig. 3. In
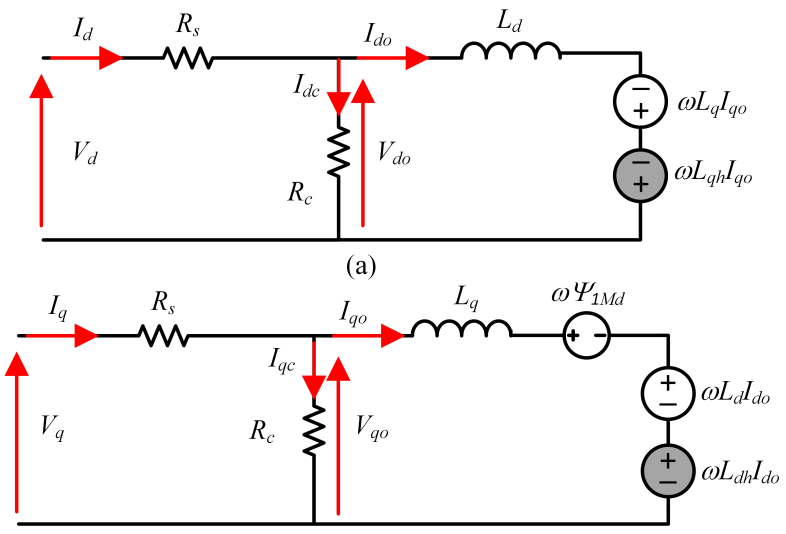

(b)

Fig. 3: Modified $d q$-axis equivalent circuit of IPM machine. (a) $d$-axis equivalent circuit. (b) $q$-axis equivalent circuit.
Fig. 3, $R_{s}$ is the phase resistance, $R_{c}$ is the core loss resistance [12], $I_{d c}$ and $I_{q c}$ are core loss components and $I_{d o}$ and $I_{q o}$ are torque producing components of $I_{d}$ and $I_{q}$. In steady state, voltage relationship for the circuit can be expressed as

$$
\begin{aligned}
& V_{d o}=-\omega L_{q} I_{q o}-\omega L_{q h} I_{q o} \\
& V_{q o}=\omega \Psi_{1 M d}+\omega L_{d} I_{d o}+\omega L_{d h} I_{d o} \\
& V_{d}=I_{d} R_{s}+V_{d o} \\
& V_{q}=I_{q} R_{s}+V_{q o}
\end{aligned}
$$

\section{ESTIMATING THE EFFECT OF SATURATION AND CROSS-SATURATION ON CONSTANT TORQUE CURVES OF IPM MACHINE}

The saturation of steel laminations changes values of $d q$ axes inductances, and causes considerable deviation between analytically predicted and measured performances of IPM machines [14]. Thus, the operating point of IPM machines can shift considerably with saturation, especially at higher load levels. A flowchart to estimate the shift in constant torque curves of an IPM machine in an $I_{d} I_{q}$-plane is shown in Fig. 4. The method uses torque equation to identify synchronous inductances from a lookup table corresponding to a set of $I_{d}$, $I_{q}$ values. Torque expression itself is a function of $I_{d}, I_{q}$ and synchronous inductances and therefore, an iterative procedure is required.

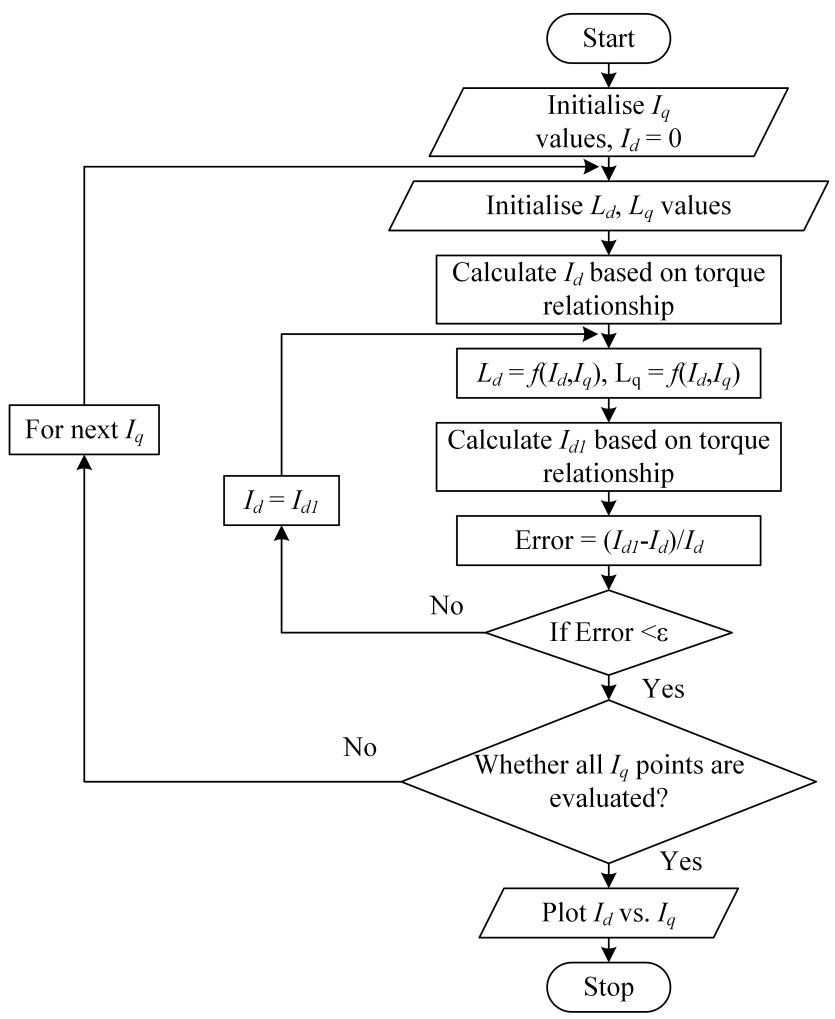

Fig. 4: Flowchart for estimating the effect of saturation and crosssaturation on constant torque curves of IPM machine (where $\varepsilon$ is a predefined error limit). 


\section{CAlCUlation OF MODIFIED $d q$-AXIS EQUivalent CIRCUIT PARAMETER FOR IPM MOTOR DESIGNS}

An overview of the specification and $d q$-axes circuit parameters of the two motors designed using the commercial design program, MotorSolve ${ }^{\mathrm{TM}}$, are listed in the table.I. Airgap

TABLE I

OVERVIEW OF SPECIFICATION AND $d q$-AXES EQUIVALENT CiRCUIT PARAMETERS OF IPM MACHINES

\begin{tabular}{|c|c|c|}
\hline Parameters & Design 1 & Design 2 \\
\hline Rotor topology & $\begin{array}{l}\text { two layer angled } \\
\text { barrier }\end{array}$ & embedded \\
\hline Rated power $(\mathrm{kW})$ & 125 & 75 \\
\hline Number of pole pairs & 2 & 3 \\
\hline Number of slots & 24 & 27 \\
\hline Rated speed (rpm) & 3275 & 3055 \\
\hline Full load torque $(\mathrm{Nm})$ & 364 & 233 \\
\hline Full load RMS line voltage (V) & 315 & 308 \\
\hline Full load RMS phase current (A) & 319 & 220 \\
\hline Outer diameter of stator $(\mathrm{mm})$ & 276 & 300 \\
\hline Stack length of stator (mm) & 193 & 281 \\
\hline Magnet flux linkage (Wb-turns) & 0.24 & 0.167 \\
\hline Phase resistance of winding $(\mathrm{m} \Omega)$ & 6.09 & 1.9 \\
\hline$d$-axis inductance at full load $(\mathrm{mH})$ & 0.34 & 0.47 \\
\hline$q$-axis inductance at full load $(\mathrm{mH})$ & 0.79 & 1.39 \\
\hline Core loss at full load (W) & 830 & 3240 \\
\hline Core loss resistance $(\Omega)$ & 119.55 & 29.28 \\
\hline
\end{tabular}

flux density distributions and its harmonics when a current of $283 \mathrm{~A}$ applied at an advancing angle $45^{\circ}$ to the design 1 and a current of $194 \mathrm{~A}$ applied at an advancing angle $45^{\circ}$ to the design 2 is shown in Fig. 5. Flux density plots of

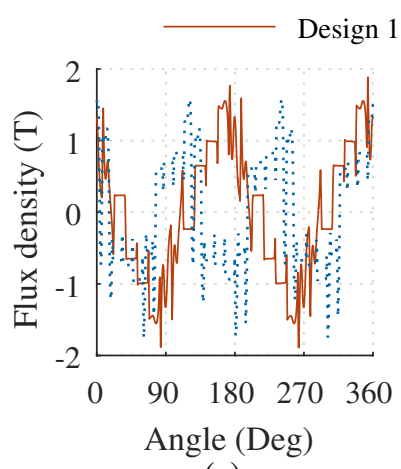

(a)

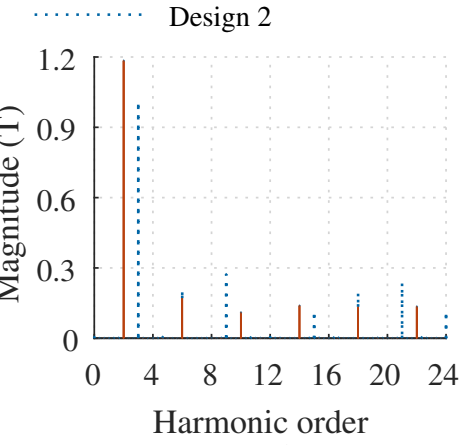

(b)
Fig. 5: Airgap flux density distributions and its harmonics when a current of $283 \mathrm{~A}$ applied at an advancing angle $45^{\circ}$ to the design 1 and a current of $194 \mathrm{~A}$ applied at an advancing angle $45^{\circ}$ to the design 2. (a) Airgap flux density distributions. (b) Flux density harmonics.

these machines for different $I_{d}$ and $I_{q}$ values are shown in Fig. 6 and Fig. 7. Harmonic inductances are calculated for harmonic orders starting from 5 to 21. The variation of $d$ and $q$ synchronous and harmonic inductances are shown in Fig. 8 and Fig. 9, and it is clear from these figures that harmonic inductance magnitudes are of the same order of synchronous inductances for the machines considered here. The value of synchronous inductances is decreasing as demagnetizing- $I_{d}$ and $I_{q}$ values are increased for two layer angled barrier rotor topology. The saturation levels of barriers (located in $d$-axis

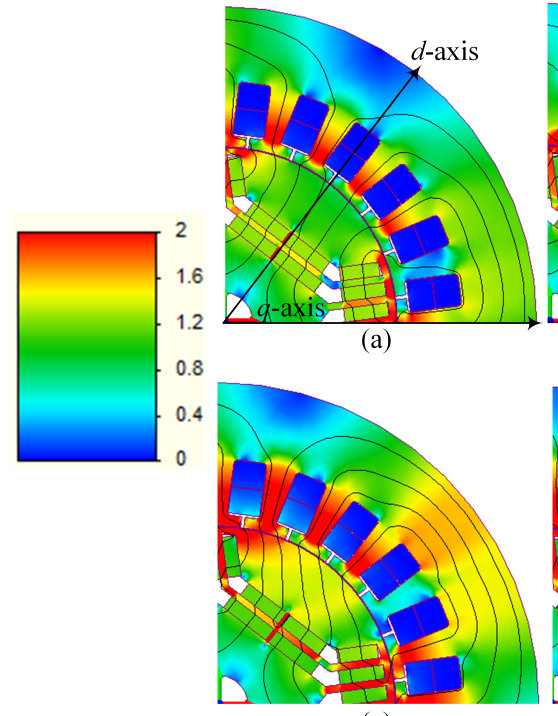

(c)

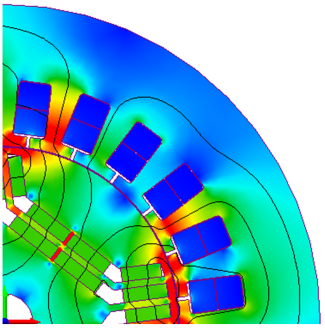

(b)

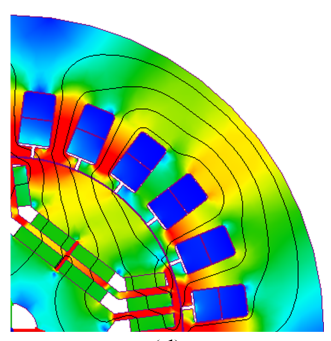

(d)
Fig. 6: Flux density (T) plots for design 1 for different $I_{d}$ and $I_{q}$ values. (a) $I_{d}=-40 \mathrm{~A}, I_{q}=40 \mathrm{~A}$,(b) $I_{d}=-280 \mathrm{~A}, I_{q}=40 \mathrm{~A}$,(c) $I_{d}=-40 \mathrm{~A}, I_{q}=280 \mathrm{~A}$ and (d) $I_{d}=-280 \mathrm{~A}, I_{q}=280 \mathrm{~A}$

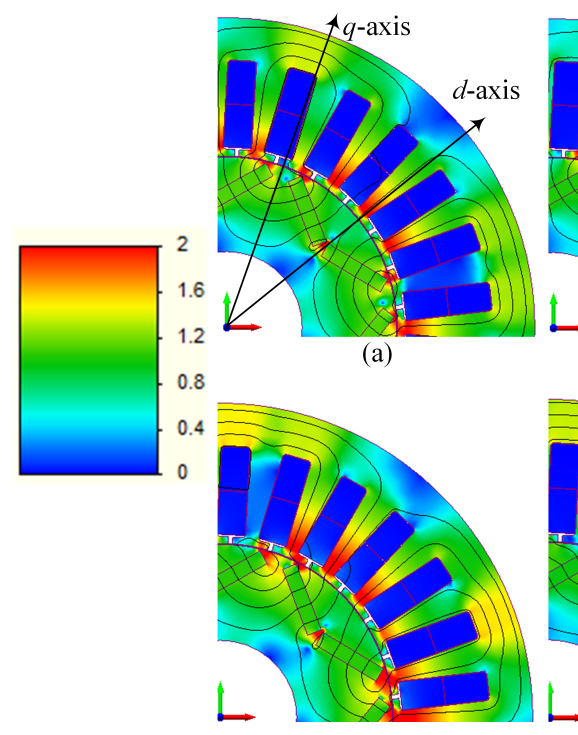

(c)

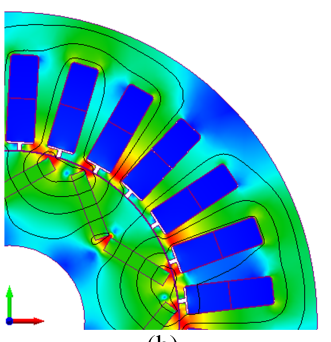

(b)

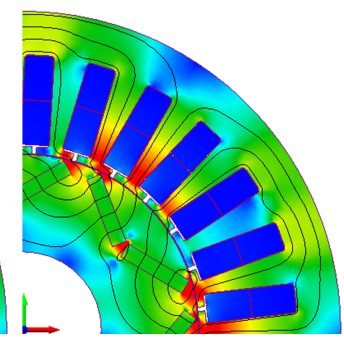

(d)
Fig. 7: Flux density (T) plots for design 2 for different $I_{d}$ and $I_{q}$ values. (a) $I_{d}=-27.5 \mathrm{~A}, I_{q}=27.5 \mathrm{~A}$,(b) $I_{d}=-220 \mathrm{~A}, I_{q}=$ $27.5 \mathrm{~A}$,(c) $I_{d}=-27.5 \mathrm{~A}, I_{q}=220 \mathrm{~A}$ and (d) $I_{d}=-220 \mathrm{~A}, I_{q}=$ $220 \mathrm{~A}$

flux path) are highly sensitive to both $I_{d}$ and $I_{q}$ as shown in Fig. 6, (b) and (c). As a result a widely spread plot of $d$-axis inductance variation is observed as shown in Fig. 8 (a). From, Fig. 6 (b) and Fig. 8 (b), it is clear that the effect of crosssaturation on $L_{q}$ is less pronounced for angled barrier IPM motor design. For embedded rotor topology, the gap between magnets located in $q$-axis is the only section of $q$-axis flux path in rotor that is highly saturated and the saturation level of this area is depended more on $I_{d}$ than $I_{q}$, resulting in $L_{q}$ and $L_{q h}$ plots that are more or less constant with variations of $I_{q}$. 


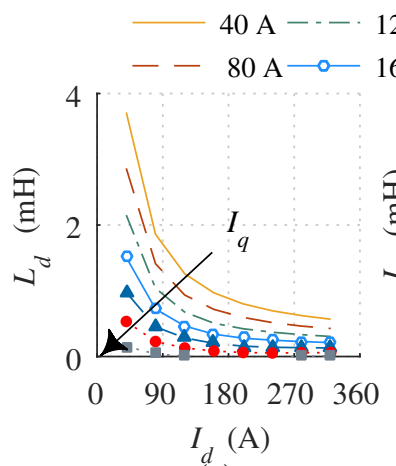

(a)

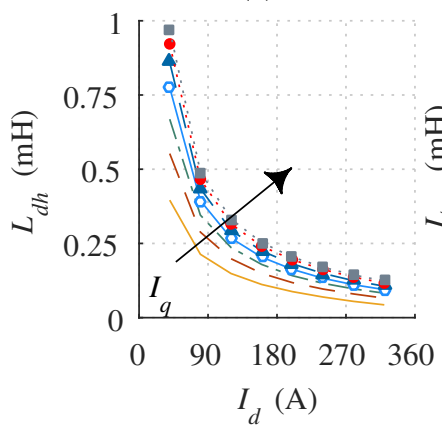

(c)

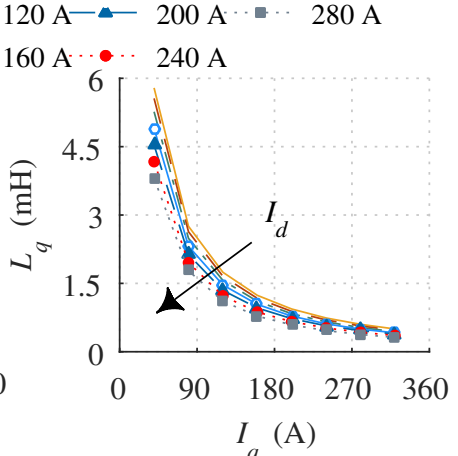

(b)

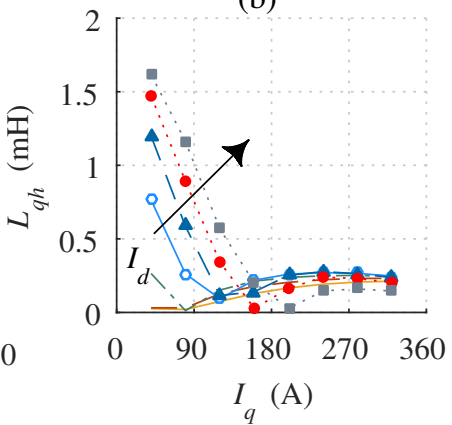

(d)
Fig. 8: The effect of saturation and cross-saturation on synchronous and harmonic inductances of $125 \mathrm{~kW}$, 4-pole, two layer angled barrier IPM machine. In this plot $I_{d}$ generates a demagnetizing field.

When the motor operates under MTPA control, the oper-

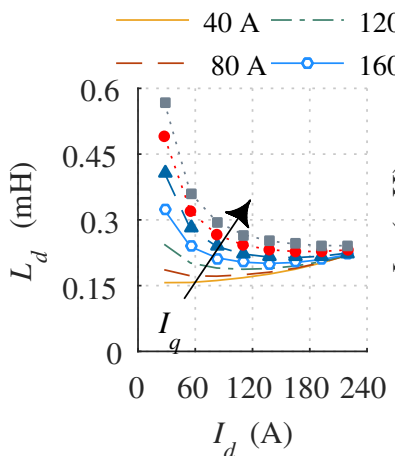

(a)

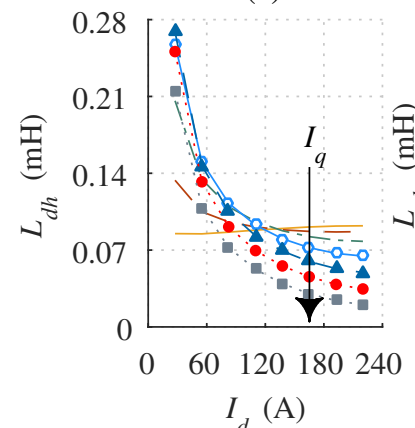

(c)

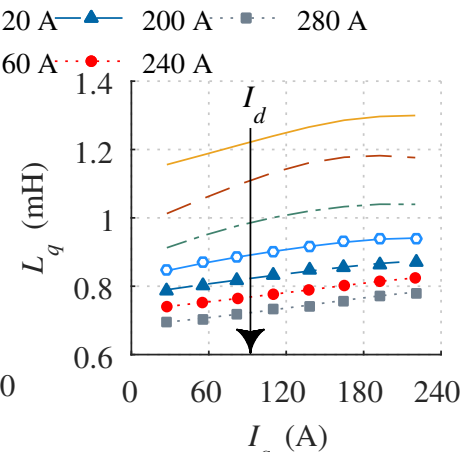

(b)
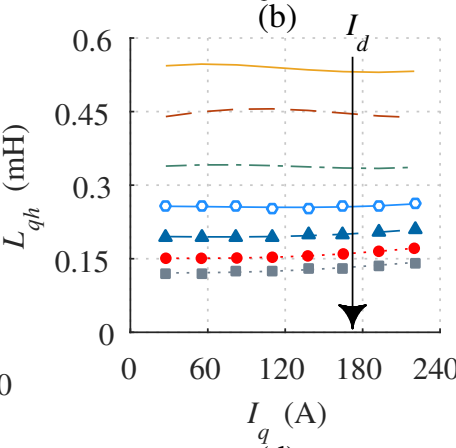

(d)
Fig. 9: The effect of saturation and cross-saturation on synchronous and harmonic inductances of $75 \mathrm{~kW}, 6$-pole, embedded IPM machine. In this plot $I_{d}$ generates a demagnetizing field. ating points will be the intersections of MTPA curve and constant torque curves. The MTPA curve for the proposed model under saturation is obtained by joining minimum current points of constant torque curves (corresponding to $50 \%$, $75 \%$ and $100 \%$ of the rated torque, $T_{r}$ ) as shown in Fig. 10. The estimated full load torque of the design 1 shows an improvement of $4 \%$ and that of the design 2 shows an improvement of $7 \%$ when saturation of the flux path and harmonic inductances are accounted in the $d q$-axes model of the machine.

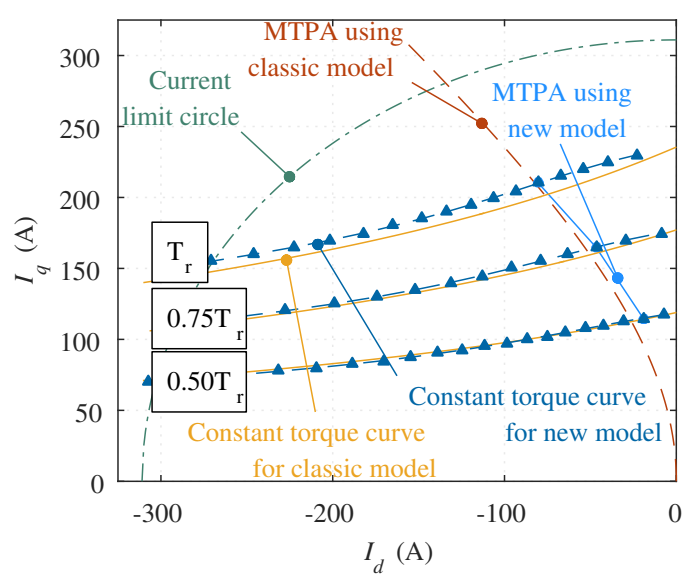

(a)

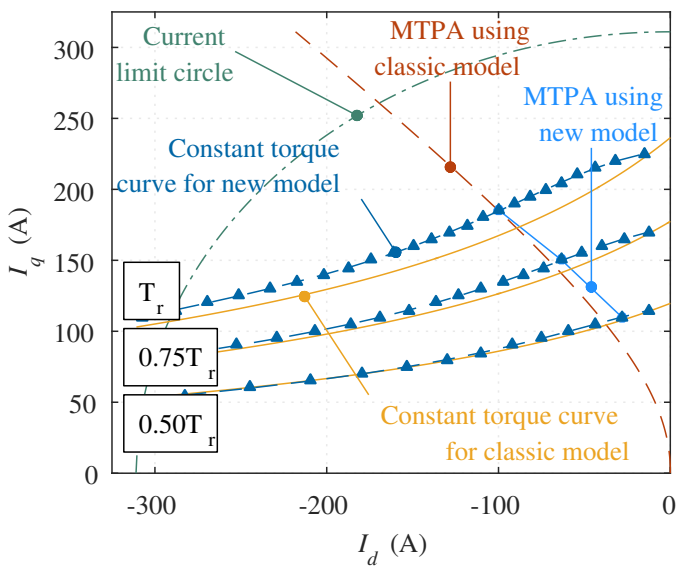

(b)

Fig. 10: The effect of saturation and space harmonics on MTPA control. (a) $125 \mathrm{~kW}$, 4-pole, two layer angled barrier IPM machine. (b) $75 \mathrm{~kW}$, 6-pole, embedded IPM machine.

\section{CONClusion}

IPM motors have higher content of airgap flux harmonics than surface magnet machines and their operation in the field weakening mode can cause the saturation of magnetic flux paths. This study proposed to add harmonic inductances to the classic $d q$-axes model of PMSM to accurately model the effect of the higher harmonic flux content of IPM motors. The analysis of two IPM machines concluded that the impact of saturation and cross-saturation on synchronous and harmonic inductances are highly influenced by the rotor topology of IPM 
machines. It has been found that discrepancy between models with and without higher order harmonic parameters can be as high as $7 \%$.

\section{REFERENCES}

[1] Z. Q. Zhu and D. Howe, "Electrical Machines and Drives for Electric, Hybrid, and Fuel Cell Vehicles," Proceedings of the IEEE, vol. 95, no. 4, pp. 746-765, Apr. 2007.

[2] J. Hendershot and T. Miller, Design of brushless permanent-magnet machines, 2010

[3] W. Soong and T. Miller, "Field-weakening performance of brushless synchronous AC motor drives," IEE Proceedings-Electric Power Applications, 1994.

[4] T. Jahns, "Component rating requirements for wide constant power operation of interior PM synchronous machine drives," in Conference Record of the 2000 IEEE Industry Applications Conference. Thirty-Fifth IAS Annual Meeting and World Conference on Industrial Applications of Electrical Energy (Cat. No.00CH37129), vol. 3. IEEE, 2000, pp. 1697-1704.

[5] A. Vagati, G. Pellegrino, and P. Guglielmi, "Comparison between SPM and IPM motor drives for EV application," in The XIX International Conference on Electrical Machines - ICEM 2010. IEEE, Sep. 2010, pp. 1-6.

[6] M. A. Rahman, "History of interior permanent magnet motors [History]," IEEE Industry Applications Magazine, vol. 19, no. 1, pp. 10-15, Jan. 2013.

[7] N. C. Kar, S. Hamidifar, and M. Kazerooni, "Analytical modelling and parametric sensitivity analysis for the PMSM steady-state performance prediction," IET Electric Power Applications, vol. 7, no. 7, pp. 586-596, Aug. 2013.
[8] Hong Chen, Dawei Li, Ronghai Qu, Zhe Zhu, and Jian Li, "An Improved Analytical Model for Inductance Calculation of Interior Permanent Magnet Machines," IEEE Transactions on Magnetics, vol. 50, no. 6, pp. 1-8, Jun. 2014.

[9] X. Chen, J. Wang, B. Sen, P. Lazari, and T. Sun, "A High-Fidelity, Computationally Efficient Model for Interior Permanent Magnet Machines Considering the Magnetic Saturation, Spatial Harmonics and Iron Loss Effect," IEEE Transactions on Industrial Electronics, vol. PP, no. 99 , pp. 1-1, 2015.

[10] Zheng Li and Hongmei Li, "MTPA control of PMSM system considering saturation and cross-coupling," pp. 1-5, 2012.

[11] G. Y. Sizov, D. M. Ionel, and N. A. O. Demerdash, "Modeling and Parametric Design of Permanent-Magnet AC Machines Using Computationally Efficient Finite-Element Analysis," IEEE Transactions on Industrial Electronics, vol. 59, no. 6, pp. 2403-2413, Jun. 2012.

[12] B.-H. Lee, S.-O. Kwon, T. Sun, J.-P. Hong, G.-H. Lee, and J. Hur, "Modeling of Core Loss Resistance for d-q Equivalent Circuit Analysis of IPMSM considering Harmonic Linkage Flux," IEEE Transactions on Magnetics, vol. 47, no. 5, pp. 1066-1069, May 2011.

[13] N. Bianchi and S. Bolognani, "Magnetic models of saturated interior permanent magnet motors based on finite element analysis," in Conference Record of 1998 IEEE Industry Applications Conference. Thirty-Third IAS Annual Meeting (Cat. No.98CH36242), vol. 1. IEEE, 1998, pp. 27-34.

[14] T. M. Jahns, G. B. Kliman, and T. W. Neumann, "Interior PermanentMagnet Synchronous Motors for Adjustable-Speed Drives," IEEE Transactions on Industry Applications, vol. IA-22, no. 4, pp. 738-747, Jul. 1986. 